\title{
Endoscopic Thyroidectomy- Preliminary Experience from a Tertiary Care Center in Delhi, India
}

\author{
Vivek Aggarwal, Bhanu Kiran Raja, Monika Garg, Deepak Khandelwal, and Bhoopendra Agarwal \\ Maharaja Agrasen Hospital, Punjabi Bagh, Delhi, India
}

DOI: https://doi.org/10.17925/USE.2017.13.01.27

\begin{abstract}
$\mathrm{C}$ osmesis after thyroid surgery has always been a concern for patients approaching thyroid surgery. To achieve a scarless surgery in the neck, endoscopic thyroidectomy using different techniques has been described in the literature. The aim of this article is to study the feasibility of endoscopic combined axillary breast approach for thyroid surgery. This is a retrospective study in the department of Endocrine Surgery from a tertiary care center in Delhi, India. Patients who underwent endoscopic thyroidectomy at our center during May 2010-November 2015 were included. The procedure was carried out in subjects who opted for the procedure with unilateral thyroid nodules of size less than $4 \mathrm{~cm}$, with benign and indeterminate cytology, and with no previous neck surgery or radiation to the neck. The details of demographic profile, operative parameters, and postoperative management were collected for all the cases. All 12 subjects were females. The mean age of the subjects was 27.2 (range 14-45) years. Mean operative time was 187 (range 110-232) minutes. There was a temporary recurrent laryngeal nerve injury in one case, local wound infection in two cases, prolonged subcutaneous emphysema in five cases, and prolonged analgesic requirement ( $>5$ days) in 10 cases. No life-threatening complications were seen in any of the subjects. Cosmetic results were excellent as there was no visible scar in the neck. The combined breast axillary approach using endoscopic technique for unilateral thyroid nodule is feasible with acceptable morbidity and can be offered to selected patients for cosmetic advantage.
\end{abstract}

\section{Keywords}

Endoscopic thyroidectomy, minimally invasive thyroidectomy, thyroid nodule

Disclosure: Vivek Aggarwal, Bhanu Kiran Raja, Monika Garg, Deepak Khandelwal, and Bhoopendra Agarwal have nothing to declare in relation to this article. No funding was received for the publication of this article.

Compliance with Ethics: All procedures were followed in accordance with the responsible committee on human experimentation and with the Helsinki Declaration of 1975 and subsequent revisions.

Authorship: All named authors meet the International Committee of Medical Journal Editors (ICMJE) criteria for authorship of this manuscript, take responsibility for the integrity of the work as a whole, and have given final approval to the version to be published.

open Access: This article is published under the Creative Commons Attribution Noncommercial License, which permits any non-commercial use, distribution, adaptation and reproduction provided the original author(s) and source are given appropriate credit.

Received: February 26, 2017

Accepted: April 10, 2017

Citation: US Endocrinology, 2017;13(1):27-29

Corresponding Author: Deepak Khandelwal, Department of Endocrinology, Maharaja Agrasen Hospital, Punjabi Bagh, Delhi-110026, India. E: khandelwalaiims@gmail.com
Ever since thyroid surgery has been described, there is ongoing evolution in the surgical techniques of thyroidectomy. The development aims at increasing safety and improving cosmesis. To achieve safety, surgeons have adopted a number of new technologies such as intraoperative neuromonitoring of recurrent laryngeal nerve (RLN), postoperative parathyroid hormone (PTH) assay, and alternative energy devices such as ultrasonic shears or bipolar coagulation. For achieving cosmesis newer surgical techniques are being validated. These are developed using endoscopic instruments and the high-density telescope which have allowed surgeons to make a smaller incision and take the line of incision away from exposed parts of the body. Any procedure, which involves using an endoscope for thyroid surgery, is often collectively called "endoscopic thyroidectomy." Since the first report of endoscopic parathyroidectomy in 1996, ${ }^{1}$ various minimal invasive approaches have been described in the literature. They could be generally classified into direct (cervical) and indirect (extracervical) approaches depending on the location of the incision. ${ }^{2}$ For the direct (cervical) approach, the small incision is made in the neck area and the thyroid gland is exposed directly, similar to the conventional thyroidectomy but with endoscopic instruments. It is the indirect methods, which give maximal cosmetic benefit but may not be truly minimally invasive as the dissection involved in raising the flap may be actually more than conventional. ${ }^{3,4}$

Cosmesis is a prime option for many of our patients approaching for thyroid surgery, especially young females who are afraid of having a scar in the neck. So, we planned to study the feasibility of endoscopic combined axillary breast approach for thyroid surgery in our set-up.

\section{Materials and methods}

This retrospective study was conducted in the department of Endocrine Surgery at Maharaja Agrasen Hospital, Punjabi Bagh, Delhi, a 400-bed teaching, superspecialty, National Accreditation Board for Hospitals and Healthcare Providers (NABH) and Joint Commission International (JCl) accredited Hospital. All cases who underwent endoscopic thyroidectomy between May 2010 and November 2015 were included. The protocol at our center for selecting patients for endoscopic thyroidectomy includes patients with unilateral thyroid nodules with benign and indeterminate cytology, less than 
Figure 1: Port being introduced via circum-areolar incision during endoscopic thyroidectomy

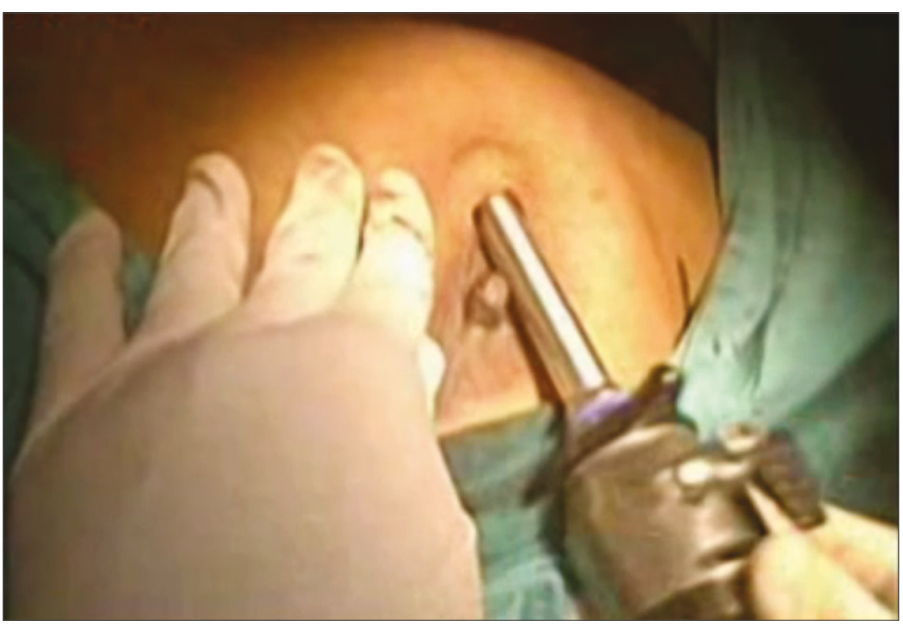

Figure 2: Thyroid nodule being dissected away from inferior polar vessels

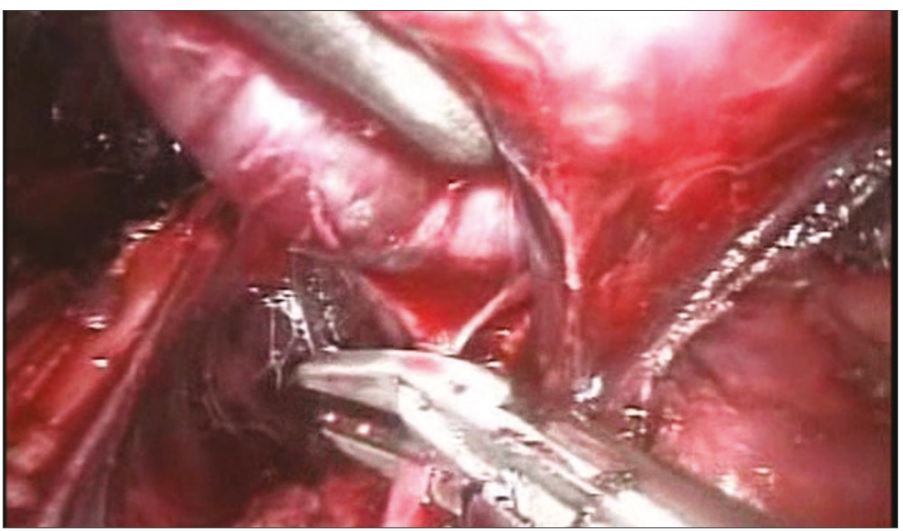

$4 \mathrm{~cm}$ with no previous neck surgery or radiation to the neck. Choice of the procedure was decided after informed and shared decision making with the patient. The details of demographic profile, operative parameters, and postoperative management were collected for all the cases. Statistical analysis was performed by the SPSS software, version 17.0 (SPSS, Chicago, Illinois). Continuous variables were presented as mean (min-max) and categorical variables were presented as absolute numbers and in percentages if required.

\section{Surgical technique}

Surgery was done under general anesthesia with same patient positioning as open thyroidectomy except placing the contralateral arm in slight extension. The lesion side arm was then raised over the patient's head to expose the axillae, and the contralateral arm was mildly abducted, in case conversion to total thyroidectomy using bilateral axillary breast approach is required. Three $10 \mathrm{~mm}$ ports were used: one in contralateral periareolar and two just posterior to contralateral anterior axillary fold 5-7 cm apart (Figure 1).

The first port was put through periareolar incision after creating a tunnel in the subdermal plane using blunt Hegar dilators until the supraclavicular
Table 1: Clinical characteristics and surgery-related outcomes of study subjects

\begin{tabular}{|l|l|}
\hline Clinical Characteristics & $\mathrm{n}=12$ \\
\hline Age in years (mean, min-max) & $27.5(14-45)$ \\
\hline Male/female & $0 / 12$ \\
\hline Tumor size in mm (mean, min-max) & $28(18-38)$ \\
\hline Operating time in minutes (mean, min-max) & $187(110-232)$ \\
\hline Duration of hospital stay in days (mean, min-max) & $2(1-3)$ \\
\hline Duration of analgesic requirement in days (mean, min-max) & $6.83(5-10)$ \\
\hline Duration of drain requirement in days (mean, min-max) & $2.5(1-4)$ \\
\hline
\end{tabular}

extent. The tract was further dilated using an indigenously designed balloon dilator. $\mathrm{CO}_{2}$ gas was insufflated at a pressure of $8 \mathrm{mmHg}$ and two working ports were then created under camera vision provided by first port. A subplatysmal working space was then created in the neck under vision. The plane between sternocleidomastoid and strap muscles was created until the omohyoid tendon could be seen. The strap was then separated in the midline and cut perpendicularly. The thyroid was exposed and retracted medially and the middle thyroid vein was cut using a harmonic scalpel. The thyroid was then retracted superiorly and laterally to expose the lower polar vessels which were either sealed or cut with a harmonic or Ligaclip ${ }^{\circledR}$ (Ethicon Inc., New Jersey, US) as appropriate (Figure 2). The RLN was identified as the lower polar vessels were dissected and lateral area of tracheoesophageal groove was cleared. Working close to the thyroid capsule, preserved parathyroids, the thyroid was then gradually lifted up and dissected from the tracheal surface. Berry's ligament was then cut taking care of the nerve and the superior pole was reached. The superior thyroid arteries were then carefully dissected and individually dealt using the combination of a Ligaclip and a harmonic scalpel. The specimen was then retracted using a sterile plastic bag and retrieved through one of the ports which was slightly widened. A drain was placed through the axillary port. Port site incision was closed using absorbable sutures.

\section{Results}

Twelve patients were included in the study. All of them were females. The mean age of the subjects of study was 27.2 years. The mean operating time was 187 minutes. None of the patients required conversion to open surgery. RLN could be identified in all the cases. At least one parathyroid was preserved on ipsilateral side for all cases. The clinical characteristics and surgical outcomes of study subjects are depicted in Table 1.

There was temporary RLN injury in one case, and local wound infection in two cases, which required the use of intravenous antibiotics. There was prolonged subcutaneous emphysema in five cases and prolonged analgesic requirement ( $>5$ days) in 10 cases. None of our cases suffered from permanent RLN injury or tracheoesophageal injury. There was no hematoma formation in any case and none required re-exploration. A postoperative drain was kept for 24 hours in all cases with no significant drainage. The cosmetic outcomes were excellent as there was no visible scar in the neck.

\section{Discussion}

In this retrospective study, we evaluated the feasibility of endoscopic thyroidectomy in Indian set-up and found that endoscopic surgery for unilateral thyroid nodule is feasible with acceptable morbidity and can be offered to selected patients for cosmetic advantage. 
Surgical scars on visible sites are always a cause of concern for the patient, especially young females. In fact, all our cases who underwent endoscopic thyroidectomy were also females only (Table 1). Postthyroidectomy scar-related apprehension among patients has forced the surgeons to develop techniques to reduce the scar and place it at less visible areas using a special endoscopic instrument. ${ }^{5,6}$ Endoscopic thyroid surgery was first successfully performed by Huscher.' Most series will suggest the use of this technique for selected cases in terms of nodule size and pathology. ${ }^{8-11}$ Many variations of endoscopic thyroidectomy have been described in terms of port placement in the literature.12,13 These can be grouped into those that use small cervical incisions, either ventral or lateral, and those that use the distant chest wall and periareolar, axillary, or combined approaches., ${ }^{5,14-19}$ Our approach was using contralateral breast and axillary approach using same instruments as in conventional laparoscopy. The only scar one gets is at the port site which is in an area not exposed and hidden by undergarments. The surgical technique is essentially the same as in conventional approach after creating a working space. We used pneumo-insufflation unlike many surgeons advocating gasless endoscopic thyroidectomy. ${ }^{20,21}$ The gas-dependent techniques can cause hypercarbia-associated complications such as subcutaneous emphysema, mediastinal emphysema, and cardiac arrhythmias and needs proper monitoring. ${ }^{22}$ However, for lower $\mathrm{CO}_{2}$ insufflation pressures, intensive end tidal $\mathrm{CO}_{2}$ monitoring $\left(\mathrm{EtCO}_{2}\right)$, intraoperative arterial blood gas analysis intermittent desufflation, and shorter operative times, proper patient selection can eliminate the risk of $\mathrm{CO}_{2}$-related complications. In our subjects, although there were no serious morbidity related to pneumo-insufflation, the resolving of subcutaneous emphysema took more than 24 hours in five cases. Previous series have documented increased operative time with endoscopic procedures as compared to conventional
Table 2: Advantages and disadvantages of endoscopic thyroidectomy as compared to conventional thyroidectomy

\begin{tabular}{l} 
Advantages \\
\hline 1. Cosmesis (no neck scar) \\
\hline 2. Better acceptability for selected patients \\
Disadvantages \\
\hline 1. Longer operative time \\
\hline 2. Only selected patients can be offered this procedure \\
\hline 3. Safety of recurrent laryngeal nerve and parathyroid glands not well established \\
compared to conventional procedure \\
\hline 4. Need more surgical expertise \\
\hline
\end{tabular}

thyroidectomy. ${ }^{10,23}$ Advantages and disadvantages of endoscopic thyroidectomy as compared to conventional surgical procedure are summarized in Table 2.

RLN could be identified in all cases but there was temporary RLN palsy in one case. The preservation of RLN close to Berry's ligament was more of a blind procedure and some thyroid tissue had to be left close to nerve to preserve it. The residual tissue versus preservation of vital structures like RLN and parathyroid needs to be assessed in bilateral surgeries before recommending these procedures for malignancies which has not been assessed in any of the series till date.

One of the major limitations of our study, apart from its retrospective nature and small sample size, was the inability to make direct comparison with conventional thyroidectomy. This is the preliminary experience of this new technique in our set-up. $\square$
1. Gagner $\mathrm{M}$, Endoscopic subtotal parathyroidectomy in patients with primary hyperparathyroidism, Br I Surg 1996;83:875.

2. Slotema ET, Sebag F, Henry JF, What is the evidence for endoscopic thyroidectomy in the management of benign thyroid disease?, World J Surg, 2008;32:1325-32.

3. Tan CT, Cheah WK, Delbridge L, "Scarless" (in the neck) endoscopic thyroidectomy (SET): an evidence-based review of published techniques, World J Surg, 2008;32:1349-57.

4. Miyano G, Lobe TE, Wright SK, Bilateral transaxillary endoscopic total thyroidectomy, J Pediatr Surg, 2008;43:299-303.

5. Rafferty M Miller I, Timon C Minimal incision for open thyroidectomy, Otolaryngol Head Neck Surg, 2006;135:295-8.

6. Hüscher CS, Chiodini S, Napolitano C, Recher A, Endoscopic right thyroid lobectomy, Surg Endosc, 1997;11:877.

7. Park YL, Han WK, Bae WG, 100 cases of endoscopic thyroidectomy: breast approach, Surg Laparosc Endosc Percutan Tech, 2003;13:20-5

8. Ohgami M, Ishii S, Arisawa Y, et al., Scarless endoscopic thyroidectomy: breast approach for better cosmesis, Surg Laparosc Endosc Percutan Tech, 2000:10:1-4.

9. Jung EJ, Park ST, Ha WS, et al., Endoscopic thyroidectomy using a gasless axillary approach, I Laparoendosc Adv Surg Tech A,
2007;17:21-5.

10. Ikeda Y Takami $\mathrm{H}$, Sasaki $Y$, et al. Comparative study of thyroidectomies. Endoscopic surgery versus conventional open surgery Surg Endosc, 2002:16:1741-5.

11. Schardey HM, Schopf S, Kammal M, et al., Invisible scar endoscopic thyroidectomy by the dorsal approach: experimental development of a new technique with human cadavers and preliminary clinical results, Surg EndosC, 2008;22:813-20.

12. Yeung GH, Endoscopic thyroid surgery today: a diversity of surgical strategies, Thyroid, 2002;12:703-6.

13. Shimazu K, Shiba E, Tamaki Y, et al., Endoscopic thyroid surgery through the axillo-bilateral-breast approach, Surg Laparosc Endosc Percutan Tech 2003;13:196-201.

14. Yeh TS, Jan YY, Hsu BR, et al., Video-assisted endoscopic thyroidectomy, Am J Surg, 2000;180:82-5.

15. Yoon JH, Park $\mathrm{CH}$, Chung WY, Gasless endoscopic thyroidectomy via an axillary approach: experience of 30 cases, surg Laparosc Endosc Percutan Tech, 2006;16:226-31.

16. Chung YS, Choe $\mathrm{JH}$, Kang KH, et al., Endoscopic thyroidectomy for thyroid malignancies: comparison with conventional open thyroidectomy, World J Surg, 2007:31:2302-6.

17. Choe JH, Kim SW, Chung KW, et al., Endoscopic thyroidectomy using a new bilateral axillo-breast approach, World I Surg 2007:31:601-6.

18. Bellantone R, Lombardi CP, Bossola M, et al., Video-assisted vs conventional thyroid lobectomy: a randomized trial, Arch surg 2002;137:301-4.

19. Yoon $\mathrm{JH}$, Park $\mathrm{CH}$, Chung WY, Gasless endoscopic thyroidectomy via an axillary approach: experience of 30 cases, Surg Laparosc Endosc Percutan Tech, 2006;16:226-31.

20. Bhargav PR, Kusumanjali A, Nagaraju R, Amar V, What is the ideal $\mathrm{CO}_{2}$ insufflation pressure for endoscopic thyroidectomy? Personal experience with five cases of goiter, World J Endocr Surg, 2011:3:3-6.

21. Gottlieb A, Sprung J, Zheng XM, Gagner M, Massive subcutaneous emphysema and severe hypercarbia in a patient during endoscopic transcervical parathyroidectomy using carbon dioxide insufflation, Anesth Analg, 1997:84:1154-6.

22. Chantawibul S, Lokechareonlarp S, Pokawatana C, Total video endoscopic thyroidectomy by an axillary approach, I Laparoendosc Adv Surg Tech A, 2003:13:295-9.

23. Kang SW, Jeong JJ, Yun JS, et al., Gasless endoscopic thyroidectomy using trans-axillary approach; surgical outcome of 581 patients, Endocr J, 2009;56:361-9. 